\title{
Mortality in rheumatoid arthritis patients with disease onset in the 1980s
}

\author{
Elisabet Lindqvist, Kerstin Eberhardt
}

\begin{abstract}
Objective-Several previous studies have shown increased mortality in rheumatoid arthritis (RA) patients. This study investigated if this was true also for patients with disease onset in the 1980s.

Patients and methods-The study group comprised 183 patients $(67$ men and 116 women) with definite RA participating in an ongoing prospective study. Mean age at onset of disease was 51 years, and mean duration of joint symptoms at inclusion was 11 months. The patients were included between 1985-89. Seventy five per cent of the patients were rheumatoid factor (RF) positive, $85 \%$ carried the shared epitope, and $90 \%$ became erosive. By 1 September 1997 the number and causes of death, obtained from the death certificates, were recorded. Standardised mortality ratio (SMR) was calculated, comparing the observed number of deaths in the cohort with the expected number of deaths in the general population in the same area, age and sex matched. The predictive values of demographics, genotype, RF status, and clinical data at baseline were estimated using the Cox proportional hazards regression model.

Results-Eighteen patients (11 men and 7 women) had died compared with 20 expected deaths. SMR with $95 \%$ confidence intervals was $87(53,136)$. There was no significant increase in the number of deaths at any time during follow up for either sex. RA was not the main cause of death in any of the cases. By reading the patient charts two cases were found where RA or its treatment could have contributed to death. No RA related variable contributed significantly to an increased risk of death.
\end{abstract}

Conclusion-There was no increased mortality during the first 8-13 years of disease in this group of patients who developed RA in the 1980s.

(Ann Rheum Dis 1999;58:11-14)

Several studies from 1953 and onwards describe rheumatoid arthritis (RA) as a disease with increased mortality. However, the reported increased risk varies considerably. ${ }^{1-9}$ Table 1 gives a summary of some of the earlier investigations. Mortality was in most of the studies expressed as standardised mortality ratio (SMR), for example, the number of deaths were compared with the expected number of deaths in the general population. Vandenbroucke et al instead reported the shortened life expectancy, which in their study was seven years for men and three years for women. ${ }^{4}$ One reason for the differences in mortality rates may be different patient recruitment and study design. Hospital based studies showed higher mortality rates than population based studies. Some of the studies were restricted to a certain patient group, for example, all patients had received thiotepa treatment ${ }^{8}$ or half of the patients were lupus erythematosus cell positive. ${ }^{4}$ In almost all investigations the patients had longstanding RA already at inclusion. ${ }^{4589}$ Only in the study by Reilly et al, were the patients followed up prospectively from the early stages of the disease. ${ }^{6}$ Their patients were included between 1957-1963. The mortality of RA patients with disease onset during the 1980s has so far not been reported. We have therefore investigated mortality rate and causes of death in an early RA cohort where the patients were included during the years 1985-1989.
Department of Rheumatology, Lund University Hospital, S-221 85 Lund, Sweden

Correspondence to: Dr Lindqvist.

Accepted for publication 2 October 1998

Table 1 Some earlier studies of mortality in $R A$

\begin{tabular}{|c|c|c|c|c|c|c|c|c|}
\hline & & $\begin{array}{l}\text { Patients } \\
(n)\end{array}$ & $\begin{array}{l}\text { Disease } \\
\text { duration at } \\
\text { inclusion }(y) \\
\text { mean }\end{array}$ & $\begin{array}{l}\text { Years of } \\
\text { follow up }\end{array}$ & $\begin{array}{l}\text { Deaths } \\
\text { (n) }\end{array}$ & $S M R$ & Selection & $\begin{array}{l}\text { Period of } \\
\text { inclusion }\end{array}$ \\
\hline 1984 & $\begin{array}{l}\text { Vandenbroucke } \\
\text { Holland }\end{array}$ & 209 & $\begin{array}{l}\text { men } 7.2 \\
\text { women } 8.5\end{array}$ & 25 & 165 & - & Rheumatology clinic & $1954-1957$ \\
\hline 1984 & $\begin{array}{l}\text { Prior } \\
\text { UK }\end{array}$ & 489 & - & $3-18$ & 199 & 300 & Rheumatology clinic & 1964-1978 \\
\hline 1986 & $\begin{array}{l}\text { Mitchell } \\
\text { USA, Canada }\end{array}$ & 805 & 10 & 12 & 233 & 150 & Rheumatology clinic & 1966-1974 \\
\hline 1990 & $\begin{array}{l}\text { Reilly } \\
\text { UK }\end{array}$ & 100 & 0.3 & 25 & 63 & 140 & Rheumatology clinic & $1957-1963$ \\
\hline 1993 & $\begin{array}{l}\text { Jacobsson } \\
\text { USA }\end{array}$ & 172 & $<2$ & $2-25$ & 79 & 130 & population & 1965-1989 \\
\hline 1994 & $\begin{array}{l}\text { Pincus } \\
\text { USA }\end{array}$ & 75 & 11.2 & 15 & 34 & 160 & Rheumatology clinic & 1973 \\
\hline 1994 & $\begin{array}{l}\text { Wolfe } \\
\text { USA }\end{array}$ & 3501 & $7.3-14.2$ & $9-35$ & 922 & 230 & Rheumatology clinic & 1965-1990 \\
\hline
\end{tabular}


Table 2 Some clinical and laboratory features in $183 \mathrm{RA}$ patients at inclusion in the prospective study. Mean disease duration at inclusion was 11 months. The data are also displayed separately for deceased and surviving patients, respectively. Values are given as median (interquartile range)

\begin{tabular}{llll}
\hline & $\begin{array}{l}\text { All patients } \\
(n=183)\end{array}$ & $\begin{array}{l}\text { Dead at follow up } \\
(n=18)\end{array}$ & $\begin{array}{l}\text { Alive at follow up } \\
(n=165)\end{array}$ \\
\hline Active joint count $(0-50)$ & $6(4-10)$ & $9(4-11)$ & $6(3-10)$ \\
HAQ disability index $(0-3)$ & $0.8(0.5-1.3)$ & $1.0(0.5-1.4)$ & $0.8(0.5-1.2)$ \\
Joint damage score $(0-200)$ & $6(3-11)$ & $11(6-23)$ & $7(3-11)$ \\
ESR $(\mathrm{mm} / \mathrm{h})$ & $29(14.5-52)$ & $25(14-39)$ & $29(14-56)$ \\
\hline
\end{tabular}

\section{Methods}

PATIENT POPULATION

The patients were participating in a prospective study of course and outcome of RA at the Lund University Hospital in southern Sweden. ${ }^{10}$ The inclusion criteria were definite $\mathrm{RA}^{11}$ with disease duration of less than 24 months and age more than 18 years. Disease duration was defined as time from onset of symptoms. Most patients were referred from primary care as a result of a special campaign to recruit cases of recent onset. At inclusion the whole spectrum of disease activity was permitted. One hundred and eighty three patients were enrolled during the years 1985-1989. There were 67 men and 116 women. The mean age (SD) at onset of the disease was $51.4(12.4)$ years and mean (SD) duration of joint symptoms at inclusion in the study was 11.1 (6.1) months. Mean follow up (SD) for all patients were 9.8 (1.9) years.

\section{CLINICAL FEATURES}

The patients were assessed every six months using standardised measures. Joint inflammation was assessed by an active joint count (defined as swollen and either tender or painful on motion). The 50 joints evaluated included all but two from the Ritchie index, namely the neck and subtalar joints. Disability was evaluated with a Swedish version of the Stanford Health Assessment Questionnaire (HAQ) disability index. ${ }^{12}$ Radiographic findings in hands and feet were scored by the Larsen method, grading changes from 0 (normal) to 5 (maximal damage). ${ }^{13}$ Thirty two joints were evaluated. The wrist score was multiplied by 5 , then all scores were added to give a joint damage score with a theoretical range of 0-200. Rheumatoid factor of IgM class was analysed with an enzyme linked immunosorbent assay (ELISA) ${ }^{14}$ HLA-DRB alleles were typed by restriction fragment length polymorphism analysis with sequence specific primers as previously described. ${ }^{15}$

\section{ASSESSMENT OF MORTALITY}

Mortality rate can be expressed as SMR, which is calculated as the ratio between the observed number of deaths in the cohort and the expected number of deaths in the general population in the same area, age and sex matched, $\times 100$. The general population has a mortality risk of 100 and results above 100 indicate an increased mortality.

In our study, comparison of observed with expected mortality was based on data of death risks in Malmöhus County, adjusted for age, sex, and year. The mortality rates in the general population for each year were used except for 1997, where the numbers from 1996 were used, as the mortality rates for 1997 were not available at the time of comparison.

By 1 September 1997 the number of deaths were recorded from the National registration. All 183 patients were checked. Because of the rigorous control system in Sweden, with a personal code number and the obligation to report all deaths to the National registration, all patients could be reliably traced. Death certificates were obtained for all patients that had died. The patient charts were studied to evaluate if RA or its treatment could have contributed to some of the deaths.

\section{STATISTICAL ANALYSES}

Cox proportional hazards model was applied to evaluate the predictive value of demographics, genotype, RF status, baseline clinical variables, and treatment during follow up.

\section{Results}

CLINICAL FEATURES

Table 2 shows the clinical and laboratory characteristics of the patients at the start of the study. The data are also displayed separately for deceased and surviving patients, respectively. Seventy five per cent were RF positive. One hundred and seventy were genotyped, 145 $(85 \%)$ of these carried the shared epitope. Fifty four $(32 \%)$ carried the epitope on both alleles. Joint damage scores were available for 151 patients. Forty eight per cent of the patients had erosions at study start. Two patients in the deceased group and 30 in the surviving group had no radiographic data at baseline. However, there were no significant differences in age, sex, genotype, RF status or clinical variables between patients with and without radiographic data.

Outcome for this cohort after five years follow up has been described before. In short radiographic changes in hands and feet increased considerably and $90 \%$ became erosive, disability remained at a fairly low level, and disease activity decreased. ${ }^{16}{ }^{17}$ Sixty two per cent were treated with disease modifying anti-rheumatic drugs (DMARDs) and 16\% with oral corticosteroids at some time during follow up. The criteria for DMARD treatment was active and progressive disease.

\section{MORTALITY}

There were 18 deaths ( 11 men and 7 women) by 1 September 1997 . The expected number of deaths was 20.6. SMR for our cohort was 87 with $95 \%$ confidence intervals of 53 to 136 . Figure 1 shows the death rate in our cohort compared with the general population. There was no significant difference in mortality rate at any point during the follow up, for either sex. Disease duration at the time of death was mean (SD) 7.8 (3.6) years, range 2-13 years. The only significant covariates in the Cox proportional hazards model were age $(\mathrm{p}<0.001)$ and $\operatorname{sex}(\mathrm{p}<0.05)$. The hazard ratios with $95 \%$ confidence intervals were for age $1.11(1.05,1.17)$ and for sex $2.62(1.01,6.78)$. Older age at onset and male sex were risk factors for death. 


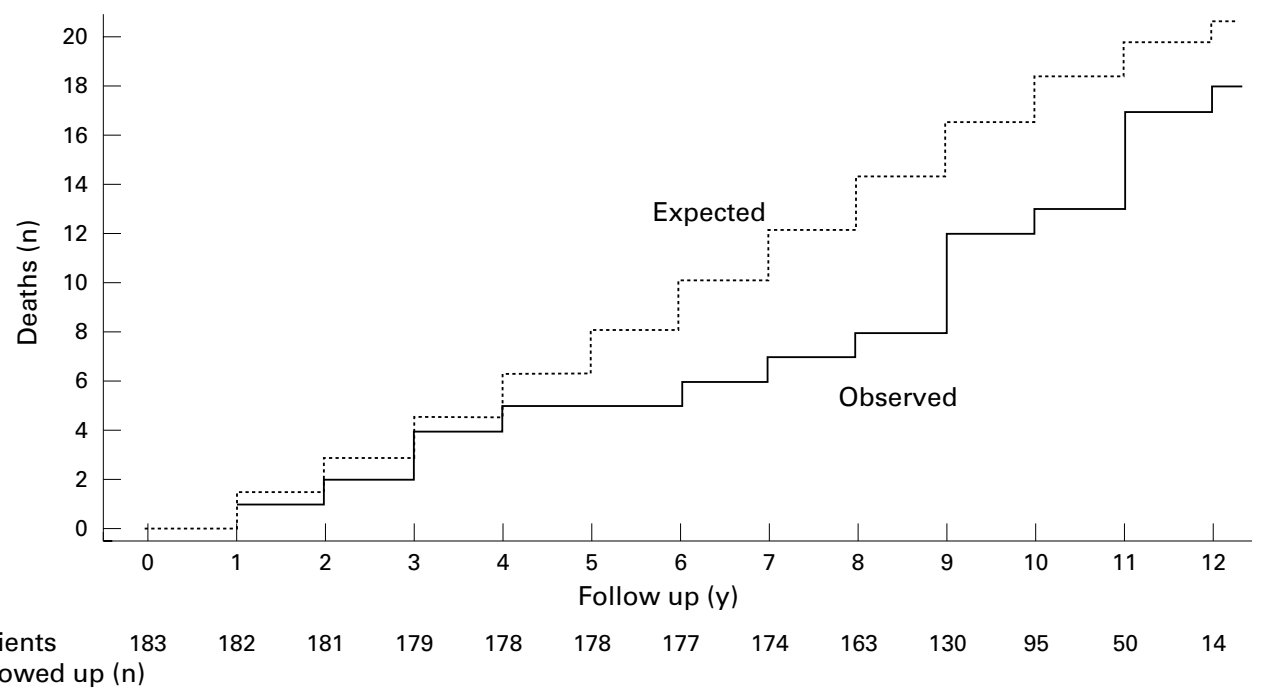

Figure 1 Number of deaths in the cohort of RA patients, compared with the expected number of deaths in the age and sex matched, general population of Malmöhus County. The number of patients followed up each year are shown under the curve.

Clinical variables, RF positivity, genotype, and drug treatment had no significant predictive value.

Table 3 shows the causes of death, taken from the death certificates. RA was not the main cause of death in any of the cases. Only four of the patients had a necropsy, two of them because they died outside hospital. In four of the 18 death certificates RA was mentioned and in all cases as a contributory condition to death. None of these patients had a necropsy.

Because of the small number of dead patients, no statistical analysis of differences in causes of death compared with the general population was performed. Half of our patients died from cardiovascular disease. In Malmöhus County $48.1 \%$ of the deaths were because of cardiovascular diseases in 1996. Seven of our 18 patients died from malignancy compared with $22.7 \%$ in the general population.

In two of the patients who died, the rheumatic disease or its treatment may have contributed to death. One was an 83 years old man who had developed RA 11 years earlier. $\mathrm{He}$ was treated with methotrexate during the last 11 months before death. He began with a dose of $7.5 \mathrm{mg}$ per week. However, after six months of treatment he developed bone marrow depression and increased liver transferase activities. The methotrexate dose was then reduced to $5 \mathrm{mg}$ per week and the laboratory tests normalised. He was admitted to hos-

Table 3 Causes of death according to the death certificates in $18 \mathrm{RA}$ patients. Mean disease duration at the time of death was 7.8 years with a range of $2-13$ years

\begin{tabular}{ll}
\hline Cardiovascular disease $(n=9)$ & Malignancy $(n=7)$ \\
2 acute cardiac infarction & 2 bronchial carcinoma \\
3 heart failure & 1 carcinoma of the kidney \\
2 coronary sclerosis & 1 carcinoma of the bladder \\
2 cerebrovascular lesions & 1 chronic monomyelocytic \\
& leukaemia \\
& 1 acute myeloic leukaemia \\
& 1 carcinoma of the collum \\
& uterus with infection \\
& postoperatively
\end{tabular}

Alcohol intoxication pital exhibiting signs of a septic shock and died a few hours after hospitalisation. Haemoglobin, leucocyte and platelet counts were low, but if this was because of infection, septic shock or methotrexate treatment is impossible to evaluate. No necropsy was done but RA was mentioned as a contributory condition in the death certificate.

The other patient was a woman, who developed mononeuritis six years after disease onset. She was treated with chlorambucil for two years and the mononeuritis resolved. She developed a myelodysplastic syndrome six months after the chlorambucil treatment was stopped and died one year later in an acute myeloic leukaemia, 58 years old. She did not have a necropsy and RA was not mentioned in the death certificate.

\section{Discussion}

In this prospective study of early RA patients we found no increased mortality with a SMR of 87. This is in contrast with previous studies where SMR varied from 130 in a population based study of Pima Indians in Arizona ${ }^{7}$ to 300 in a hospital based study from Birmingham. ${ }^{3}$ Our follow up is so far only 10 years, and no certain conclusions can therefore be drawn about longer term outcome. In most previous studies mean disease duration was about 10 years already at inclusion. ${ }^{458}$

The study design might have influenced mortality rate. In prospective studies comprising patients followed up from the early stages of disease, milder cases may not have been lost to the same extent as in studies starting at a later stage. In our study inclusion was permitted irrespective of disease activity and as shown in table 2 median disease activity at baseline was fairly low. Only two thirds of the patients were treated with DMARDs. At the five year follow up the untreated patients had considerably less joint damage progression, ${ }^{17}$ reflecting that we also had cases with milder disease. However, despite this, if there is any bias in our cohort, it is more towards severe disease taking features 
such as genotype, RF status, and erosiveness in consideration.

The study from Bath is the most comparable to ours both regarding study design and patient characteristics such as age and sex. After 25 years follow up they reported a SMR of $140 .^{6}$ After about the same length of follow up as ours, they reported 17 deaths among 100 patients. ${ }^{18}$ This seems higher than in our study, but the figures are not completely comparable, as they at this stage did not calculate SMR.

The disease onset of the patients from Bath was almost 30 years earlier than the disease onset of the patients in our cohort. Maybe RA has become a milder disease as suggested by Silman. ${ }^{19}$ Modern drug treatment to patients with aggressive disease, and emphasis on maintaining physical abilities by team care and patient education may also have contributed to improvement of outcome, even mortality.

The mere fact that our patients participated in a prospective study may have contributed to lower mortality. General health surveillance is probably better, and for instance high blood pressure and diabetes may be detected and treated earlier than in the general population.

No disease related factor at onset could predict death in our cohort. In many previous studies bad functional status ${ }^{5-9} 20$ and positive $\mathrm{RF}^{479}$ were risk factors for premature death.

In this study treatment with oral corticosteroids was not associated with death, which is in contrast with some earlier findings. ${ }^{9}{ }^{20}$

Causes of death did not seem to differ substantially from the general population. In other studies deaths resulting from infections were usually increased..$^{4-6920}$

We found only two cases with a possible connection between RA and the death. Similar frequency was reported by Vandenbroucke et $a l^{4}$ while in the study from Bath ${ }^{6}$ one third of the deaths were considered to be attributable to RA, either as the direct cause or as contributing factor.

Only four patients had a necropsy. The necropsy rate in Sweden has decreased from about $50 \%$ in the beginning of the 1970 s to $19 \%$ in $1996 .{ }^{21}$ The decrease is mainly in elderly people and especially where the death is because of stroke and ischaemic heart disease. However, a necropsy apparently does not improve the information given in the death certificates regarding the possible role of RA. This disease was not recorded in any of the death certificates of the necropsied patients. RA was mentioned in four death certificates and in only one of the two patients where we suspected that it had contributed to death. This shows the uncertainty of evaluating death causes by means of death certificates.

To conclude, the main reason for our low mortality and low number of deaths associated with RA might still be the short disease duration. However, it is an important finding, both for the patient and the physician, that mortality in patients who developed RA in the 1980s was not increased during the first 10 years of disease.

Grants were obtained from The Medical Faculty of Lund, The Österlund and Kock Foundations, the King Gustaf V 80-year Fund, and Reumatikerförbundet.

The authors wish to thank Jan-Åke Nilsson for excellent assistance with the statistical analyses.

1 Cobb S, Anderson F, Bauer W. Length of life and cause of death in rheumatoid arthritis. N Engl J Med 1953;249:553-6.

2 Symmons DPM. Mortality in rheumatoid arthritis. $\mathrm{Br} \mathrm{J}$ Rheumatol 1988;27 (suppl 1):44-54.

3 Prior P, Symmons DPM, Scott DL, Brown R, Hawkins CF. Cause of death in rheumatoid arthritis. Br J Rheumatol 1984;23:92-9.

4 Vandenbroucke JP, Hazevoet HM, Cats A. Survival and cause of death in rheumatoid arthritis: a 25 -year prospective follow up. J Rheumatol 1984;11:158-61.

5 Mitchell DM, Spitz PW, Young DY, Bloch DA, McShane DJ, Fries JF. Survival, prognosis, and causes of death in rheumatoid arthritis. Arthritis Rheum 1986;29:706-14

6 Reilly PA, Cosh JA, Maddison PJ, Rasker JJ, Silman AJ Mortality and survival in rheumatoid arthritis: a 25 -year prospective study of 100 patients. Ann Rheum Dis 1990;49:363-9.

7 Jacobsson LTH, Knowler WC, Pillemer S, Hanson RL, Pettitt DJ, Nelson RG, et al. Rheumatoid arthritis and mortality: a longitudinal study in Pima Indians. Arthritis Rheum 1993;36:1045-53.

8 Pincus T, Brooks RH, Callahan LF. Prediction of long-term mortality in patients with rheumatoid arthritis according to simple questionnaire and joint count measures. Ann Intern Med 1994;120:26-34.

9 Wolfe F, Mitchell DM, Sibley JT, Fries JF, Bloch DA, Williams CA, et al. The mortality of rheumatoid arthritis. Arthritis Rheum 1994;37:481-94.

10 Eberhardt K, Rydgren LC, Petersson H, Wollheim FA. Early rheumatoid arthritis - onset, course and prognosis over 2 years. Rheumatol Int 1990;10:135-42.

11 Ropes MV, Bennet GA, Cobb S, Jacox R, Jessar RA. Diagnostic criteria for rheumatoid athritis. Ann Rheum Dis 1959;18:49-53.

12 Ekdahl C, Eberhardt K, Andersson SI, Svensson B. Assessing disability in patients with rheumatoid arthritis. Use of a Swedish version of the Stanford Health Assessment QuesSwedish version of the Stanford Health Assessm
tionnaire. Scand J Rheumatol 1988;17:263-71.

13 Larsen A, Dale K, Eek M. Radiographic evaluation of rheumatoid arthritis and related conditions by standard reference films. Acta Radiol Diagn (Stockh) 1977;18:48191.

14 Truedsson L, Sjöholm AG, Sturfelt G. Complement activating rheumatoid factors in rheumatoid arthritis studied by haemolysis in gel: relation to antibody class and response to treatment with podophyllotoxin derivates. Clin Exp Rheumatol 1985;3:29-37.

15 Eberhardt K, Fex E, Johnson U, Wollheim FA. Associations of HLA-DRB and DQB genes with two and five year outcome in rheumatoid arthritis. Ann Rheum Dis 1996;55: come

16 Eberhardt KB, Fex E. Functional impairment and disability in early rheumatoid arthritis - development over 5 years. J Rheumatol 1995;22:1037-42.

17 Fex E, Eberhardt KB. Development of radiographic damage during the first 5-6 year of rheumatoid arthritis. A prospective follow-up study of a Swedish cohort. Br J Rheumatol 1996;35:1106-15.

18 Jacoby RK, Jayson MIV, Cosh JA. Onset, early stages, and prognosis of rheumatoid arthritis: a clinical study of 100 prognosis of rheumatoid arthritis: a clinical study of

patients with 11-year follow-up. BMJ $1973 ; 2: 96-100$.
19 Silman AJ. Are there secular trends in the occurrence and severity of rheumatoid arthritis? Scand J Rheumatol severity of rheumatoid a

20 Corbett M, Dalton S, Young A, Silman A, Shipley M. Factors predicting death, survival and functional outcome in a prospective study of early rheumatoid disease over fifteen years. Br J Rheumatol 1993;32:717-23.

21 The National Board of Health and Welfare, centre for epidemiology. Stockholm: Statistics - health and diseases. Causes of death 1996. Official statistics of Sweden. 